\title{
Information Systems for Leading and Managing Schools: Changing the Paradigm
}

\author{
C.J. P. Nolan and M. Lambert \\ Massey University, Palmerston North, New Zealand \\ Fax: +6463513325 \\ E-mail:P.Nolan@massey.ac.nz
}

Key words: Information Systems, Schools as Organisations, Learning Community, Paradigm Shift, School Case Studies

Abstract: Although schools in New Zealand have long viewed themselves, and functioned, as organisations, experience and research show that they must, in the future, increasingly develop and operate as learning communities to be educationally effective. This paper examines the extent to which three schools have been able to employ a widely used state of the art computerised information system in ways that support theiroperation and development as learning communities. Findings, from case studies of the schools, show that two factors are key in enabling school personnel to use the system effectively: (1) the strength of commitment by school leaders and teachers to learning community principles, and (2) the technical understanding and know-how of the principal particularly and, to a lesser extent, the staff, rather than system characteristics or design features. Discussion suggests new directions for the design of computerised school information systems and the need to reformulate common understandings of what might count as "good systems" for schools that either operate, or aspire to operate, as learning communities.

\section{INTRODUCTION}

Over the last ten years in New Zealand, the adoption and use of computerised schoolinformation systems (CSIS) has dramatically increased. The manner in which they are used, however, varies markedly between schools (Nolan and Ayres, 1996). Moreover, a correlation seems to exist between types of school culture and use patterns. For instance, secondary 
schools tend to have more teachers than primary schools with the capability and experience to use a wide range of administrative and management programs. It seems, though, that they use them to perform quite specific oneoff tasks, reflecting perhaps the segmented organisational cultures of secondary schools. Moreover, when the programs are used to carry out higher order functions, this activity tends to be confined within a school's management team. In contrast, it is far more common for primary schools, using somewhat fewer computer resources, to makekey data about the school (e.g. details of the school budget) available to the whole staff, reflecting thereby a sense of community more than organisation. In a primary school, as community, the collaborative solving of problems and the shared making of decisions tend to prevail. In secondary schools, this approach is not well understood and it appears, as yet, to be seldom used (Nolan and Ayres, 1996).

Beyond these global variations, all schools in New Zealand share the common attribute of having to meet mandated requirements emanating from government policies of school accountability. Over the last decade or more, schools have been required by law to regularly submit reports on many aspects of school operations, assess student achievement and report results against pre-specified achievement objectives, and demonstrate that mandated programme delivery requirements have been met. The methods of accountability are enshrined in the Government's National Education and Administration Guidelines (NEGS and NAGS) that detail specifically the requirements to be met and the manner of meeting them. Designers of computerised systems have responded accordingly by providing schools with the kinds of administrative and management programs they require. These are capable of both the automating and informating functions identified by Visscher (1996), but it is conjectured here that their utility lies more in how they assist schools to demonstrate accountability than support school development.

The dramatic increase of CSIS adoption and use mentioned above has undoubtedly caused schools to change their administrative and management systems in line with the NEGS and NAGS, with consequent internal changes to organisational functioning as well. The extent and nature of the latter varies by type of school and by school level (Ayres, Nolan and Visscher, 1998). It could be said that the organisational functioning of schools nationally has stabilised around varyingly low to high levels of computerised administrative efficiency and effectiveness in meeting the requirements that have been persistently made of them. Moreover, schools have developed adroitness in the computerised management ofinformation (Visscher, 1996), although the adroitness undoubtedly varies between schools.

As in most countries, New Zealand schools are always subject to political whim. The lessons of recent history say that schools must be on guard 
constantly to ensure that systems and procedures, along with the culture and organisation of the school, are sufficiently robust to manage change that can be mandated by government at any point. This is especially the case at times when the government changes, as it did it late 1999.

Ifgovernment guidelines of the last decade defined an "accountability for outcomes" and a "compliance" role for school administration and management, changes to them in early 2000 , immediately following the change of government, now specify that schools will exercise "accountability for processes" rather than outcomes, as their first priority. One might argue that the focus now will be much more on developing the technical core of the school (Fulmer, 1995), i.e. the enhancement of learning and teaching, improvement to the quality of programmes, and the utilisation of computerised school information systems to these ends.

In this enterprise, the definition of school management is likely also to change, with greater value being placed on the exercise of educational leadership whose purpose is to achieve educational ends as much as accountability ones. At the school level, the shift is, in effect, a shift from educational organisation to learning community as the paramount concept behind the work of a school.

By implication, a shift will be required in the design of computerised school information systems away from the organisational and accountability system concepts of the past and towards classroom-focused information systems (Frank and Fulmer, 1998). In New Zealand, this shift is already happening, but in making it system designers appear to have retained the underlying spreadsheet and data base design approaches and philosophy that they have used habitually in the past. The software produced for teachers by application of these approaches and philosophy has enormous "processing power". Senior school managers and administrators and some teachers are increasingly applying this power to enhance the professionalism of teachers working in the "technical core". But anecdotal reports indicate that teachers are struggling to adapt and use to good effect software programs and systems that were, in effect, designed for a different purpose, i.e. to meet accountability demands.

\section{PURPOSE}

In this paper we present case studies of three schools which function, by and large, as learning communities. The studies report how the schools are attempting to implement, though not without difficulty, "state of the art" computerised school information system programs, of the kind referred to above, to support their learning community focus and develop it further. 
Discussion of findings from the studies: (1) examines directions for computerised school information system design of the future; (2) proposes modifications to our understanding of what might count as a "good system"; and (3) suggests ways that leadership and management, supported by use of computerised systems, might better assist the development of schools as learning communities in the future.

\section{METHOD}

The particular schools were selected for two main reasons. Firstly, they operate in ways that experience, policy and research suggest schools might operate and develop in the future as learning communities (see the discussion below that illustrates the learning community concept). Secondly, they were judged to be typical of schools that both perceive themselves, and are perceived by others, as effective users of computerised school information systems. The case studies illustrate the efforts by the schools to implement effective development and implementation practices. They do not, and could not, document the full range of good development and implementation practice and they do not deal with "unsuccessful" practices, other than in the sense of documenting difficulties encountered and problematic aspects of use. In this respect, the studies simply begin the process of systematically researching the development and implementation challenges that schools and system developers will face and have to address in the future.

Data were collected through direct observations and first hand accounts of system adoption, implementation and use in each school. These were augmented by focused, in-depth interviews with the full range of individuals involved, including school board members, teachers and school administrators, directly and indirectly associated with developments, support agency staff and system developers. The case studies summarise the data in the form of accounts of the situation in each school regarding the role and effects of the computerised information systems.

\section{BACKGROUND}

Primary schools were studied because they best illustrate the concept of learning community in action whereas secondary schools operate more typically as organisations and only in rare instances as communities. In the New Zealand education system, primary schools cater, in the main, for the needs of children aged between 5 and 11 years and they range in size from 1- 
2 teachers to $30+$ teachers. The schools of this study are of comparable size (approximately 10 teachers and 200 students each) and they all use the MUSAC (Massey University School Administration by Computer) school information system, but vary slightly with respect to the specific programs used.

MUSAC software is used in over 2000 schools, or $75 \%$ of all New Zealand schools. The MUSAC system, a comprehensive and integrated suite of programs (see the MUSAC website - http://musac.massey.ac.nz - for a full description), has been re-designed over the past three years to include programs for teacher as well as administrator use. It encompasses all aspects of the administration and management of schools as outlined in the School Information System Framework developed by Visscher (1996) and it includes specific programs teachers can use in their classrooms and other work places to support curriculum planning and delivery. In this respect, the MUSAC system conforms to the concept of a classroom focused information system (Frank \& Fulmer, 1998). Moreover, previous research (Nolan \& Ayres, 1996) has demonstrated that the MUSAC system satisfies the technical criteria of a "good system" in that it can be employed to "collect data, automate processes and informate the work of multiple decision makers from different organisational levels" (Fulmer, 1995). Its bottom-up design and incorporation of a help desk and a user group facility means that the system is responsive to user needs.

All three schools commonly employ the generic MUSAC Pupil Files database program which stores the full gamut of student demographic and personal data (e.g. name, address, caregivers, age, siblings, health). Data in Pupil Files may be integrated with data from all other programs. It permits the seamless transfer of information between programs and comparative and correlational analyses of data from different programs, e.g. absences related to test scores and participation in sport correlated with academic performance. The case studies document the ways in which each school complements its use of Pupil Fileswith other programs. These include:

- Progress Monitor for recording and analysing data on all aspects of student performance;

- Library Manager for managing all aspects of the operation of the school library including student use and borrowing patterns; and

- Classroom Manager for supporting teacher management of classroom curriculum programmes and school-wide programme planning and review. 


\section{LEARNING COMMUNITIES IN ACTION}

All three schools exhibit in their mode of operation, and in their cultures, features that identify themas learning communities. These features include:

1. Activities that establish and develop, as necessary, shared understandings, beliefs and values central to the school culture;

2. The collective determination of school wide goals, priorities and directions;

3. The delegation of responsibility to teacher syndicates for all curriculum planning, implementation and review;

4. Collaborative development of the school budget and the allocation of resources by consensus; and

5. Collegial review of programmes within and across syndicate boundaries and staff workshops to identify and share best practices regarding learning, teaching and the assessment of student performance.

While these features predominate to a greater or lesser extent in all three schools, each school also functions to some extent as an organisation in respect to:

1. Meeting mandated requirements (e.g. submitting monthly financial reports to the School Board and quarterly reports of students enrolled to the Ministry of Education); and

2. Ensuring, day to day, that routine administrative tasks are executed efficiently, e.g. the production of myriad lists relating to, for example, class scheduling and the organisation of extra curricula activities, the operation of the school library and tracking the flow of shared teaching resources between classrooms and syndicates.

By and large, senior administrators and office staffuse the MUSAC software programs identified above to perform the administrative work of making their schools function smoothly as "organisations". The extent and frequency of their use in this way varies between the schools, The variation, in its turn, reflects differences between school personnel in familiarity with the software and corresponding differences in their competency and confidence to use it. Teaching staff in each school are encouraged to employ the software, or outputs generated by it, in relation to features which identify the schools as learning communities, though with varying success as detailed below in the case study accounts.

In each school, the principal plays a key role encouraging staff at all levels to develop the knowledge and skills they need. The exercise of this 
role by the principal distinguishes the three schools from many, perhaps most, other primary schools. This is because, in the schools selected for study, the principals have a clearly developed vision of the role that a CSIS might play and they clearly articulate the vision to staff and the school community. Decisions regarding software and hardware acquisition are taken either by the staff as a whole or by the principal in consultation with the staff.

This approach is consistent with the notion of community, in which no one person has the right to make unilateral decisions on matters that affect the welfare and development of the community and its members. In this respect, all the schools operate a form of "citizen democracy" (Saul, 1995). That is to say, all members are accorded respect as persons and as capable professionals and the power and authority associated with particular positions is downplayed in favour of a more collegial approach.

A variety of factors appear to affect the way in which CSIS use can, and actually does, facilitate the realisation of "citizen democracy" in each school and assist them to function effectively as communities in the full sense to which they each aspire. The factors include: features ofthe software, e.g. its design philosophy and approach and user support strategies; the levels and kinds ofCSIS knowledge and capability distributed among staff; attitudes of support or resistance among staff; and the organisational and cultural conditions prevalent in each school.

The case studies provide accounts of the way that the factors, both on their own and in interaction with each other, are pressing the schools to operate and develop in particular directions. The overall modus operandi of each school is indicated by its location on the diagonal in Figure 1 below. The diagonal is the dividing line that distinguishes a school that operates predominantly as an organisation from one that operates as a learning community. This way of depicting the difference captures the idea that while any given school may operate predominantly as a community, it will contain, inevitably, organisational elements, e.g. as reflected in the presence of hierarchical management positions, even though the importance of these may be de-emphasised.

Use of the diagonal in this way indicates the present modus operandi, but suggests the possibility that while a school may be operating in a particular way at any given time, its mode of operation may change and thus its location on the diagonal. This may happen for any one or a number of reasons, e.g. the appointment of staff members who subscribe to a different view or the implementation of a school development process. As Figure 1 shows, location of the three schools at the top of the diagonal indicates that they presently operate as learning communities in the manner described above. 


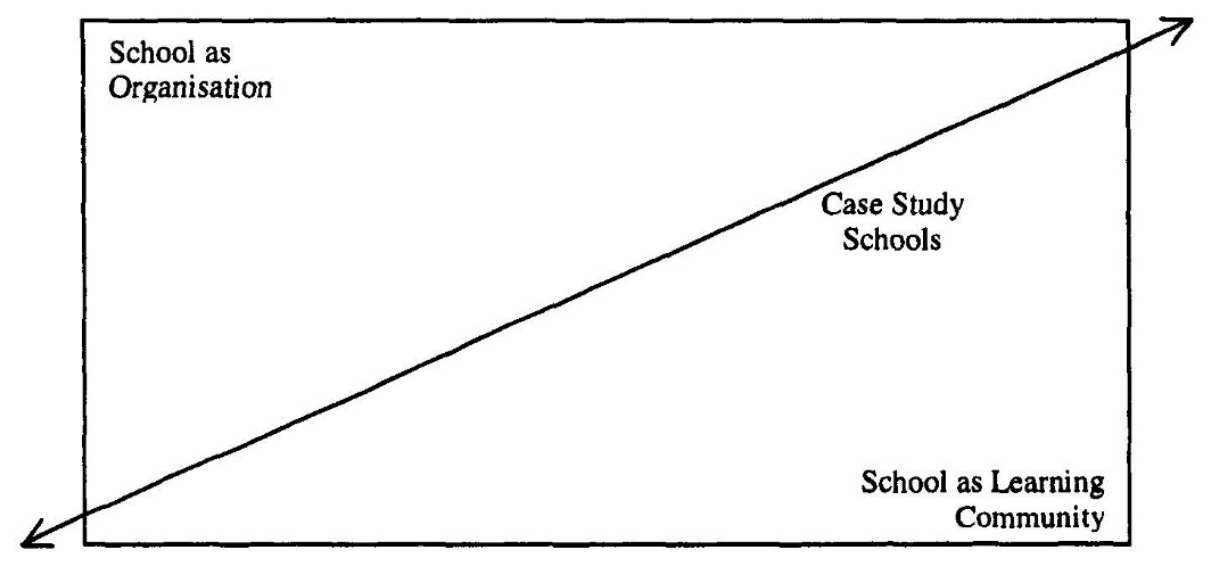

Figure 1.Model of schooloperation and development

\section{CASE STUDIES}

\subsection{School One}

During school-wide review and planning meetings at year's end and at the beginning of each new school year, the staff of School One collaboratively develops year-long learning and teaching programmes to be implemented across the whole school. The programmes reflect a staff consensus that designated learning areas and skills should feature centrally in any given year. For instance, the staffas a whole decided that the development of selfesteem, literacy and numeracy should feature centrally as school wide themes in 2000. In this way the staffas whole addressed specific needs that were identified by the school community at the end of the preceding year as requiring special and ongoing attention. To this end, the school both adopted and adapted two MUSAC programs, Progress Monitor and Pupil Files, to generate the data and information on student performance that both the school and parents would need.

The programs were adopted because, in tandem, they provide the means to store, correlate and analyse student performance data generated from three main sources linked to:

1. Teacher-defined achievement objectives for the various essential learning areas and essential skills of the national curriculum, along with literacy, numeracy and self-esteem objectives; 
2. Learning goals and associated objectives developed by the students and incorporated into classroom programmes; and

3. Standardised tests in a range of key areas, e.g. National Progressive Achievement Tests in Reading, Mathematics and Study Skills and School EntryAssessment.

Data from the standardised tests provide the school administrators, as well as teachers, with an independent measure of student progress. Interestingly, in this school, the principal himself enters the performance data from each source into the MUSAC Classroom Manager program. Additionally, the principal utilised Classroom Manager to institute and maintain a schoolwide register of extra and co-curricula activities and interests, along with special needs information to reflect the school's learning community philosophy to develop the whole child.

The programs had to be adapted, however, because the principal and staff considered that default output, in the form of numerical tables and graphs, was an inappropriate way, on its own, to record and report student progress and performance. This was especially so in light of school policy to use student portfolios for assessment, and compile "annual assessment profiles" for each student. The latter served also as a cumulative achievement record to be transported from one class level to the next and between schools. It proved to be particularly useful with children who returned to the school aftera period elsewhere.

The production of these profiles necessitated the special "tailoring" of Progress Monitor output so as to produce meaningful information for teacher use and reports that were comprehensible to parents. For instance, in order to illustrate specific accomplishments and progress, along with learning difficulties, in the various learning areas, anecdotes were incorporated in reports through the use of additional (adjunct) functions especially inserted into the program by the developer. These especially created functions are Progress Monitor "templates" used to construct annual assessment profiles. If the CSIS is well utilised, this is due in large measure to the determination of the principal and staff to make the system fit the school rather than the school fit the system.

This school routinely implements a school-wide school development process to review programmes, share best practices, and develop shared understandings around values, goals and directions, The process relies heavily on such techniques as narrative accounts, story telling and the summation of written reports, including ideas and resources gleaned from the professional literature on school and curriculum development and allied topics. Yet, little if any of this work is supported by the CSIS. The explanation given by the principal and various staff is that the system does 
not lend itself readily to processing qualitative data and information germane to their school development and improvement processes.

\subsection{School Two}

In School Two, the principal developed and promoted school-wide, and in the school community, a view that education with ICT (information and communication technology) should feature increasingly in school programmes. ICT should be used primarily as tools for learning, but also as administration and management tools that teachers could employ for school decision making and the development of school policy. Over time, this view was incorporated into school policy and in the three years since the principal's appointment, all computers available for teacher use (one per teacher) were upgraded and networked. Consistent with school policy, both teachers and administrative staff are being provided with the professional development and training they need, although this is less with CSIS than with learning and teaching applications.

MUSAC Pupil Files, used extensively for the past six years, and MUSAC Progress Monitor, used for the last three, are now employed in tandem in a manner similar to School One. MUSAC Library Manager is utilised mainly as a stand alone library administration and management tool, with its integration capabilities being employed from time to time for school wide purposes, e.g. analysis of class borrowing patterns linked to family circumstances such as socio-economic status and ethnicity. Such a use is evidence of the principal's growing ability to utilise the informating functions of the software. Unlike the principal of School One, however, his approach is to generate standard numerical and graphing reports to show trends and patterns.

Both the principal and staff are aware that such use, unless carefully controlled, can produce data and information for its own sake rather than serve a useful purpose such as to inform decisions or help develop policy. For example, in 1999, the whole staff reported and recorded swimming ability levels "which they graphed in many ways". They came to see this as futile, however, because their analyses produced results that served nouseful purpose!

Although this school operates by and large as a learning community, the use of the CSIS reflects more nearly an organisational model, as shown perhaps in its predominant use by the principal for addressing accountability requirements, and corresponding use by staff to complete standardised forms. This is not to gainsay the fact that the school and its staff operate effectively as a community, and, in contrast with CSIS use, ICT is generally integrated well into classroompractice. 


\subsection{School Three}

In this school, the principal has a developing vision of the role that a CSIS might play to support administration and management functions and the role of ICT as providing educational tools. The vision is based upon many years of experience of using computers and helping others to use them. Recently, the school was commended by the Educational Review Office as a "moving school" in the sense of demonstrating collaborative professional development practices linked to ICT. These are promoted and encouraged by the principal and they are the means by which staff members assist each other to develop awareness and mastery of the administrative and management tools available to them in the MUSAC Classroom Manager program. The collaborative practices include: peer coaching, externally facilitated training workshops, team meetings to share good ideas, planning cooperatively how to use the program, and an informal "buddy system" to support self directed learning.

The professional development programme is a key means by which the staff, working with the principal, is developing a shared vision for the implementation and use of information technology school-wide, including a plan for use of the CSIS. Two specific developments are occurring simultaneously: (1) installation of an intra-net for linking all computers school-wide and then providing all teachers with remote access to the CSIS; and (2) ongoing professional development and training to increase the skills of both teachers and administrative staff in CSIS implementation and use (see Nolan, Ayres and McKinnon, 1996 for an account of the staff development strategies employed).

The vision, developed internally, is being adopted by the School Board of Trustees and they, along with the principal and staff, are promoting the vision in the school community as signaling a preferred direction for future school development.

In this development, the principal and the staff, working together, are gradually translating the overall vision into commitment to:

1. Generate documentation for parents that report student progress quarterly;

2. Gather data and information, especially on student achievement and attitudes, more objective than that presently available;

3. Identify and record systematically the learning needs of students through consultation with caregivers and the students themselves, and link the needs thus identified with national achievement objectives as specified in National Curriculum Statements; and 
4. Develop computerised procedures to record, monitor and report student progress against school-based achievement criteria, as well as (and in time perhaps as an alternative to) the normative criteria of national standardised tests.

By moving the school in these directions, the principal and staff indicate their more deep-seated commitment to learning community goals and objectives. This is reflected specifically in the principal's goal to replace, in a relatively short time, conventional computer generated reports with digital portfolios. This development is currently being frustrated through lack of CSIS capability to produce the desired result.

\section{CONCLUSIONS}

At the 1998 ITEM Working Conference, one participant warned that continuing to design CSISs for existing educational structures, simply making the structures more efficient than they are now, is likely to inhibit change and development, not promote it (Nolan et al., 1998). The case studies illustrate how three schools, wanting to change and develop, found that their state of the art systems helped them to administer and manage efficiently but often did not provide the means to review and develop programmes or chart new directions at the school level. Principals and other school personnel commonly saw use value in conventional spreadsheet generated results and information, e.g. reports on the academic progress of students. They also commonly required other kinds of results and information, however, that their existing systems could not readily produce, e.g. the digitised portfolios referred to in Case Study 3.

Findings from the case studies reported here support conclusions of the 1998 Conference delegates that "good" CSISs of the future must:

1. Incorporate in their designs a social vision of school which empowers rather constrains learners and teachers (sic, dramatically more than is possiblenow with existing systems);

2. Embody design concepts broad enough to accommodate the full range of information contained in schools; and

3. Build in features which increase the likelihood that stakeholders' rights of access to, and use of, information can be realised.

The incorporation of these features in system designs of the future would be consistent with the findings of contemporary school development research (Day, 2000; Hopkins et al., 1994; Sergiovanni, 1996; Stewart et al., 1997) 
and the experience of the schools reported in this paper. That is to say, schools must increasingly operate as learning communities with shared decision making and shared access to the data and information upon which the making of decisions is based. Such a shift will require an adjustment in our basic assumptions and thinking about the nature and operation of educational institutions, and their computerised information systems, that is akin to a paradigm shift (Kuhn, 1970).

Findings from all three case studies show that two factors are key in enabling school personnel to use their existing systems effectively and take initial steps towards making the paradigm shift: (1) the strength of commitment by school leaders and teachers to learning community principles, and (2) the technical understanding and know-how of the principal particularly and, to a lesser extent, the staff rather than system characteristics or design features (Visscher, 1996).

For instance, in School One, the principal used his technical knowledge to adapt the CSIS, thereby enabling him and other staff members to operate the school along learning community lines, for example by incorporating student nominated achievement objectives into curriculum programmes and assessment procedures. In School Two, the system was adopted and implemented "as is" by the principal and staff. They were no less committed to the learning community model, but their lack of technical knowledge constrained them from using the system in support of learning community goals to the same extent. An unintended effect was that the principal's management and leadership style becamemore "organisationally orientated" than he realised or intended. In School Three, the principal, who understood the shortcomings of the system, knowingly adopted it but he did so with the explicit realisation that it would have to be modified.

An important implication of the studies is that senior school personnel and teachers must be acknowledged to be now, and in the future, the key factor in the ability of schools to effectively and fully utilise their (expensive) computerised systems to support the operation and development of schools. This is the case for two reasons.

Firstly, these personnel either possess or can learn the technical skills required. This aspect of the situation must not be under-rated. Even though designers strive to make their systems user friendly and intuitively useable, their effective use will require technical competency and confidence much more than can be acquired just by reading a manual or picking up the necessary knowledge by word of mouth. A further implication, then, is that schools must be prepared to invest in the professional development of staff much more than in the past.

Secondly, school personnel (teachers, senior administrators and managers, and office staff especially) understand the nature of the data and 
information they need upon which to make informed judgements and decisions about directions for development at classroom, programme and school levels. These data and information encompass much more than is typically permitted by school administration and management software designed around conventional alpha/numeric database and spreadsheet formats. Such formats, now intrinsic to good software designs, will remain so. But, the designs of the future will be much broader in scope and more accommodating than they are now of the inherent complexity, sophistication and subtlety of professional life and work in educational institutions.

By and large, the effect of New Zealand's National Education and Administration Guidelines, imposed by successive governments, has been to focus the attention of school leaders and managers on meeting accountability expectations, operating the school smoothly as an organisation and producing results. Teachers have been expected to assess students against a myriad of pre-set Achievement Objectives. The conscientious execution of this task has directed their attention, and that of school leaders also, towards performance as an organisation and away from ways by which to function better as learning communities. In the climate that has produced this effect, teachers are trusted less as responsible professionals, they are expected to comply with externally imposed expectations, and professional commitment is valued less than in the past. Compliance has tended to replace consent as a motive for action. The computerised school information systems designed and developed in this climate have, by and large, embodied principles and precepts consistent with the concept of the school as an organisation generating mandated returns, processing normative data, and calculating and reporting performance statistics.

Computerised systems for schools of the future may still be required for these purposes. Increasingly their purpose will be to support, however, development in ways that take account of and deal with the complexity, sophistication and subtlety mentioned above. As this development unfolds, educational professionals at all levels will review and reflect upon their practice and strive to improve it. In this enterprise, narrative and stories will increasingly become the objects of analysis and communication using computerised systems somewhat more sophisticated and multi-media capable than they are now. 


\section{REFERENCES}

Ayres, D., Nolan, C.J.P., \& Visscher, A.J. (1998). Computer-based school information systems: Researching New Zealand use patterns and levels of use. In C.L. Fulmer, C.J.P. Nolan, \& B.Z. Barta (Eds.), The integration of information for educational management. Whitefield, Maine: Felicity Press.

Day, C. (2000). Beyond transformational leadership. Educational Leadership, 57 (7), 56-59.

Frank, F.P., \& Fulmer, C.L. (1998). Paper presented at the International Working Conference on Information Technology and Educational Management. Christmas Cove, Maine, USA.

Fulmer, C.L. (1995). Maximising the potential of information technology for management strategies for interfacing the technical core ofeducation. In B.Z. Barta, M. Telem, \& Y. Gev (Eds.) Information technology in educational management. London: Chapman Hall.

Hopkins, D., Ainscow, M., \& West, M. (1994). School improvement in an era of change. London: Cassell.

Kuhn, T.S. (1970). The structure of scientific revolutions. Chicago: Chicago University Press.

Nolan, C.J.P., \& Ayres, D.A. (1996). Developing a "good" information for schools: The New Zealand experience. International Journal of Educational Research, 25 (5), 307-319.

Nolan, C.J.P., Fulmer C.L., \& Taylor, R.G. (1998). Four computerised school information systems: Summary discussion. In C.L. Fulmer, C.J.P. Nolan, \& B.Z. Barta(Eds.), The integration of information for educational management. Whitefield, Maine: Felicity Press.

Saul. J.R. (1995). The unconscious civilization. Concord, Ontario: House of Anansi Press.

Sergiovanni, T.J. (1996). Leadership for the schoolhouse: How is it different? Why is it important? San Francisco: Jossey-Bass Publishers.

Stewart, D.J., Prebble, T., \& Duncan, P. (1997). The reflective principal: Leading the school development process. Katonah, New York: Richard C. Owen Publishers.

Visscher, A.J. (1996). Information technology in educational management as an emerging discipline. International Journal of Educational Research, 25 (4), 291 -296. 